Elsevier

GENE 03277

\title{
Sumo15A: a lambda phasmid that permits easy selection for and against cloned inserts
}

(Recombinant DNA; amber mutation; cloning vectors; dnaB; Escherichia coli; gene libraries; suppressor)

\section{Sumiko Kurachi, Nedra Baldori and David M. Kurnit}

Departments of Pediatrics and Human Genetics, Howard Hughes Medical Institute, University of Michigan Medical Center, Ann Arbor, MI 48109-0650 (U.S.A.)

Received by D.M. Skinner: 23 August 1988

Revised: 8 August 1989

Accepted: 10 August 1989

\section{SUMMARY}

We report the construction of a phasmid vector, Sumo15A, designed for recombination-based screening of recombinant DNA libraries [Seed, Nucleic Acids Res. 11 (1983) 2427-2445]. This vector permits rapid selection in Escherichia coli for homology-mediated integration and excision between homologous DNA inserts cloned in a supF-carrying plasmid and in Sumo15A. The region available for recombination spans the homologous sequence shared by the plasmid and the phasmid. SupF is the selection tool that we used. Efficient selection for sup $F$ expression by Sumo15A requires recombination mediated by the $\lambda$ phage red gene, which promotes homologous recombination between phage and plasmid DNAs. Counterselection against supF expression by Sumo15A occurs because the presence of a pSC101-derived plasmid replicon in this phasmid permits the growth of Sumo15A as a plasmid in a specialized host, E. coli strain DK37. In strain DK37, Sumo15A cannot replicate as a phage, and the presence of a plasmid-carrying supF is lethal to cells plated on galactose plates. This scheme was developed to select for sequences that are transcribed from chromosomes of interest.

\section{INTRODUCTION}

The recombination-based assay developed by Seed (1983) accomplishes the rapid screening of complex libraries cloned in a bacteriophage $\lambda$ vector

Correspondence to: Dr. S. Kurachi, Departments of Pediatrics and Human Genetics, Howard Hughes Medical Institute, University of Michigan Medical Center, 1150 W. Medical Center Drive, Ann Arbor, MI 48109-0650 (U.S.A.) Tel. (313) 747-4747; Fax (313)936-9353.

Abbreviations: bp, base pair(s); Bluo-gal, halogenated indolyl $\beta$-D-galactoside; cDNA, DNA complementary to RNA; cfu, by a probe nt sequence cloned in a plasmid that carries supF. To select for reversal of this recombination reaction, we designed a counterselection scheme against phages carrying supF. This counterselection scheme yields phages that have deleted the

colony-forming units; $\mathrm{Cm}$, chloramphenicol; $\Delta$, deletion; $\nabla$, insertion; EtdBr, ethidium bromide; gp, gene product; IPTG, isopropyl- $\beta$-D-thiogalactopyranoside; $\mathbf{k b}$, kilobase(s) or $1000 \mathrm{bp}$; LB, Luria-Bertani broth; NRE, no-cut right end; nt, nucleotide(s); pfu, plaque-forming units; ${ }^{R}$, resistance; $s$, sensitivity; $\mathrm{Sm}$, streptomycin; SOD, superoxide dismutase; $S O D-1$, gene encoding SOD; Sp, spectinomycin; [ ], denotes plasmid-carrier state. 
sup $F$ plasmid plus probe nt sequence by reversing the forward recombination reaction. These are the reasons for requiring counterselection.

(1) Continued integration of the probe nt sequence could interfere with the characterization and mapping of the original phage DNA insert.

(2) The frequency of excision via recombination reflects the extent of homology between the probe sequence in the plasmid and the target insert sequence in the phage. Cointegrants that excise only infrequently can be discarded on the presumption that they resulted from illegitimate (Ikeda et al., 1982; Marvo et al., 1983) or poorly matched recombination events (Huang et al., 1987).

(3) Continued integration of the plasmid prevents repeated use of the recombination-based procedure, e.g., to monitor the directionality of a recombinationbased chromosome walk.

A variety of strategies were tried, unsuccessfully so far, to interfere with $\lambda$ lytic growth using a sup $F$ gene carried by the phage. In contrast, supF has been shown to prevent plasmid propagation in a specialized host (Russell et al., 1970). To utilize the latter counterselection against sup $F$ expression by plasmids in a specialized $E$. coli host, we constructed a $\lambda$ phasmid vector, Sumo15A, that is compatible with the recombination-based assay between $\lambda$ phages and ColE1 supF plasmids. This vector can be used in its phage state to select for the integration of $\sup F$ via shared homology, and in its plasmid state to select against $\operatorname{supF}$.

In other work, we demonstrated that the dnaB266am (P1ban) host (DK21) can be utilized to select for phages carrying supF (Kurnit and Seed, 1990). In DK21, suppression of the $d n a B$ am allele by sup $F$ is required for phage propagation. We discovered that ColE1 replicons could propagate in the dna $B^{-}$environment of DK21, whereas pSC101 replicons could not. This explains why placement of a ColE1 replicon into a phage vector aborts the dnaB am selection (Kurnit and Seed, 1990), whereas the placement of a pSC101 replicon has no effect on this selection scheme. The purpose of the present study was to construct a phasmid vector, Sumo15A (derived from phage $\lambda$ Charon $15 \mathrm{~A}$, and the $\mathrm{pSC101-}$ derived plasmid, pGB2; Churchward et al., 1984), that permits selection for and against the integration by homology of ColE1-driven supF-containing plasmids into the phasmid vector, Sumo15A. In so doing, we extended the utility of the recombinationbased assay (Seed, 1983) by demonstrating the feasibility of performing this assay in both the forward and reverse directions.

\section{RESULTS AND DISCUSSION}

\section{(a) Construction of Sumo15A}

Sumo15A combines the phage properties of $\lambda$ Charon 15A (Blattner et al., 1977) with the plasmid properties of the pSC101-derived plasmid, pGB2 (Churchward et al., 1984). Sumo15A (Fig. 1) was constructed by replacing the nonessential $2-\mathrm{kb}$ EcoRI-HindIII fragment of $\lambda$ Charon 15A with the 4-kb EcoRI-HindIII fragment that spans all but the polylinker of pGB2 (Churchward et al., 1984). The resulting phasmid, Sumo15A, has features of both parent vectors: it will replicate as a lytic phage unless the host expresses appropriate $(\phi 80)$ immunity, in which case it will replicate as a plasmid driven by the pSC101-derived replicon of pGB2.

We used a pSC101-derived replicon in Sumo15A because pSC101 does not replicate in DK21, i.e., a dnaB266am (P1ban) host (Kurnit and Seed, 1990). Therefore, the insertion of the pGB2 plasmid into the Sumo15A phasmid does not circumvent the dnaB amber selection in DK21. Further, pSC101 does not share homology with ColE1 plasmids, as documented by the lack of hybridization between pGB2 and ColEl plasmids (Churchward et al., 1984). To ensure that Sumo15A was neither rescued from the $d n a B$ am selection by the $\mathrm{pSC} 101$ replicon nor shared any homology that might promote undesired phasmid-plasmid recombination in the assay, we monitored the frequency of recombination between the ColE1-driven sup $F$-carrying plasmid $\pi$ Flee (Fig. 2) and Sumo15A (Table I; Neve and Kurnit, 1983). This frequency was about $10^{-9}$, equal to the low illegitimate recombination frequency observed between $\pi$ Flee and the parent phage, $\lambda$ Charon $15 \mathrm{~A}$. This low recombination frequency was also observed between $\pi$ Flee and a human fetal brain cDNA library constructed in Sumo15A. Thus, the insertion of pGB2 into $\lambda$ Charon 15A did not significantly affect the frequency of phage-ColE1 plasmid recombination. 


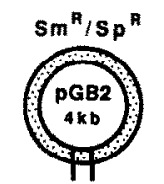

HindIII EcoRI

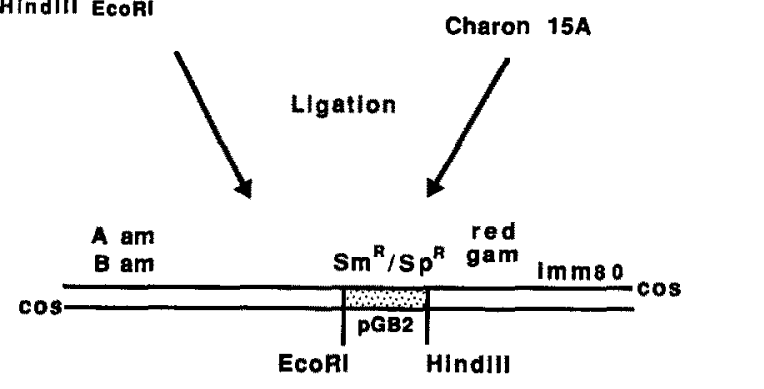

\section{Sumo15A}

Insertion vector: $8.4 \mathrm{~kb}$ capaclty

Fig. 1. Construction of Sumol5A phasmid. The phage insertion vector, $\lambda$ Charon15A (A am32 Baml b1007 imm 80 KH53 BW2 nin 5 NRE) accepts inserts from $0-10.4 \mathrm{~kb}$ that may be ligated into unique EcoRI, HindIII, SalI or XhoI cloning sites (Blattner et al., 1977). Charon15A is well-suited for use with the recombination-based assay of Seed (1983), as it is recombinationproficient ( $\mathrm{red}^{+}$), and carries $A$ and $B$ amber mutations that decrease background in the assay following selection on DK21 (dnaB 266am) to negligible levels (D.M.K. and B. Seed, in press). pGB2 (Churchward et al., 1984) is a pSC101 (Linder et al., 1983)-derived plasmid that confers both $\mathrm{Sm}$ and $\mathrm{Sp}$ resistance, and carries the HindIII-EcoRI polylinker from pUC8 (Vieira and Messing, 1982). Two important differences of pGB2 from ColE1derived replicons are that $\mathrm{pGB} 2$ does not share sequence homology with ColE1-derived plasmids (Churchward et al., 1984), and both $\lambda$ and pSC101-derived replicons do not replicate in the dnaB266am (P1ban) host environment of DK21 (D.M.K. and $B$. Seed, in press) that permits $E$. coli and ColE1 plasmid replication. Phasmid vector, Sumol5A, was constructed by replacing the nonessential 2-kb EcoRI-HindIII fragment of Charon15A (Blattner et al., 1977) with the 4-kb EcoRI-HindIII fragment of pGB2 (Churchward et al., 1984). Since Sumo15A gained $2 \mathrm{~kb}$ in size from the parent Charon $15 \mathrm{~A}$, this phasmid vector has a capacity of $0-8.4 \mathrm{~kb}$ for inserts. Sumo15A inherited $E c o R I, H i n d I I I, S a l I$, and $X$ hol cloning sites from $\lambda$ Charon15A.

\section{(b) Recombination between $\pi$ Flee-SOD and} Sumo15A-SOD: a reconstruction experiment

As shown in Table I, the recombination frequency between $\pi$ Flee-SOD (Fig. 2) and Sumo15A in the absence of homology was about $10^{-9}$. In the presence of perfect homology shared between the $1.3-\mathrm{kb}$ $H$ indIII SOD inserts in $\pi$ Flee-SOD and Sumo $15 A-$ SOD (Fig. 3), the recombination frequency was $5 \times 10^{-3}$. In a reconstruction experiment, dilution of Sumo15A-SOD phages with Sumo15A resulted in
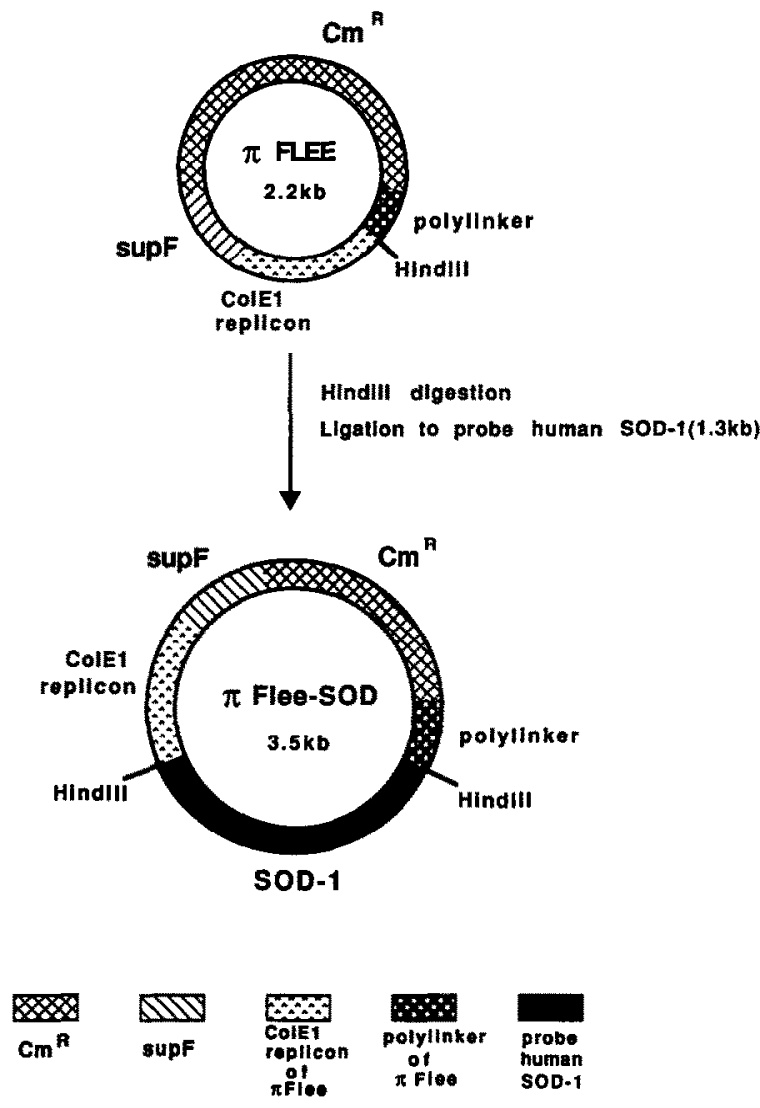

Fig. 2. $\pi$ Flee mini plasmid. $\pi$ Flee was constructed by inserting a 1.3-kb flush-ended $\mathrm{Cm}^{\mathrm{R}}$ element into $\pi \mathrm{AN} 13$ at the unique $X m n I$ site (Huang et al., 1987; Lutz et al., 1987), and thus yielded an approx. 2.2-kb ColE1 supF $\mathrm{Cm}^{\mathrm{R}}$ plasmid (F. Lee and D.M.K., unpublished). $\pi$ Flee-SOD was constructed by inserting a $1.3-\mathrm{kb}$ HindIII fragment of $S O D-1$ (Groner et al., 1985) into the $H i n d I I I$ cloning site of $\pi$ Flee, yielding a $3.5-\mathrm{kb}$ plasmid that conferred supF and $\mathrm{Cm}^{\mathrm{R}}$. These plasmids were established by conferral of $\mathrm{Cm}^{\mathrm{R}}$ to the E. coli $\mathrm{K}-12$ strain MC1061 (Table I).

progressively lower frequencies of recombination. At the greatest dilution ( $1 \mathrm{pfu}$ Sumo15A-SOD $/ 10^{7} \mathrm{pfu}$ Sumo15A), the homologous recombination frequency approached the frequency of illegitimate recombination $\left(10^{-9}-10^{-10}\right)$. Thus, we could not distinguish homologous recombination from nonhomologous recombination using only the forward rate of recombination. However, utilizing the ability to counterselect against phasmids carrying $s u p F$, we demonstrate below that the two phages isolated at this lowest dilution indeed resulted from recombination between the homologous SOD-1 sequences in $\pi$ Flee-SOD and Sumo15A-SOD. These experiments also confirm that the presence of pGB2 does not alter recombination between $\lambda$ Charon $15 \mathrm{~A}$ 
TABLE I

Recombination between $\pi$ Flee or $\pi$ Flee-SOD and Sumol5A or Sumol5A-SOD ${ }^{a}$

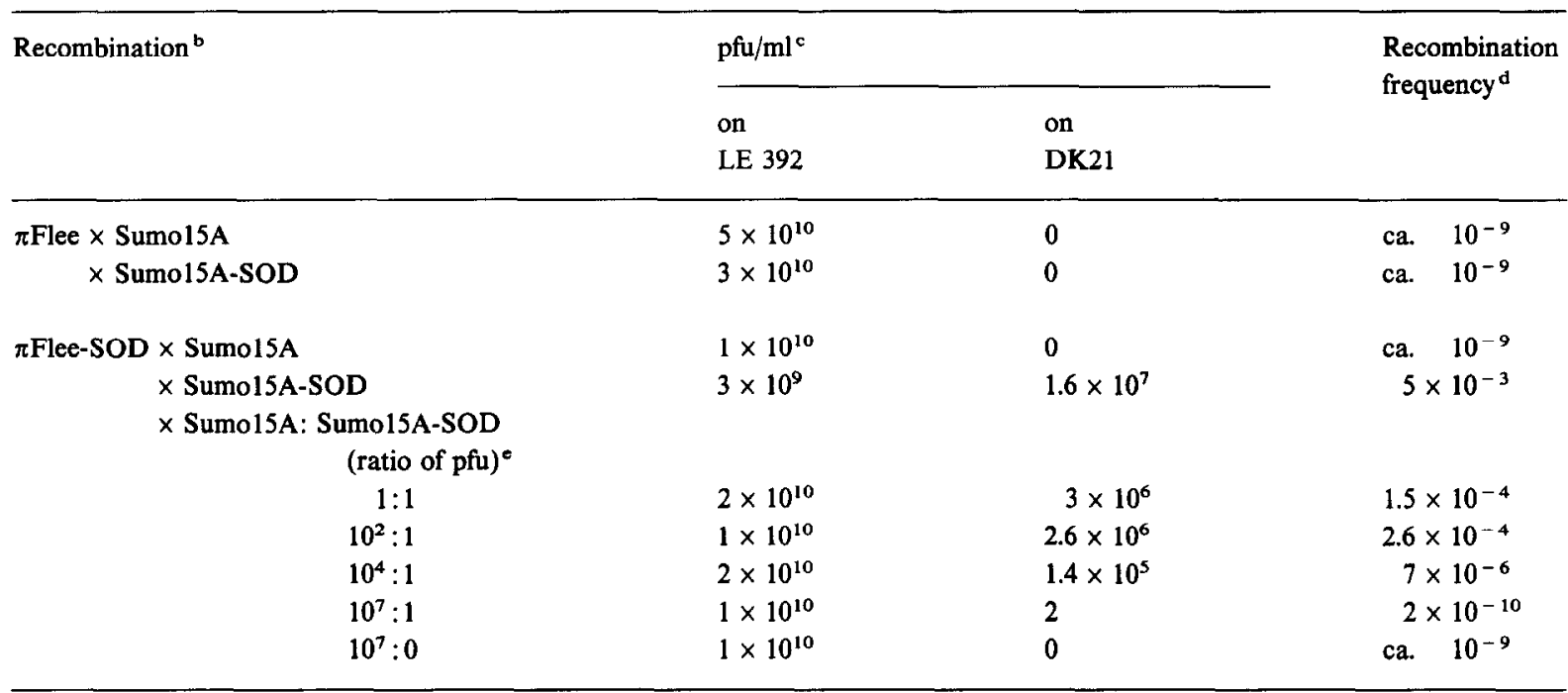

a As given in the text, the E. coli K-12 strains utilized to monitor recombination include: (1) LE392: $h s d R 514$ (hsdR ${ }^{-} h s d M^{+}$), supE44, supF58, lacY1, galK2, galT22, metB 1, trpR55 (L. Enquist, E.I. DuPont, Wilmington, DE); (2) DK21: lacZ am, dnaB266am, Sm ${ }^{\mathrm{R}}$ ( $\lambda b 515$ b519 attP P1ban imm 21 nin 5) (Kurnit and Seed, 1990); and (3) DK37: $\Delta\left(\right.$ srl-recA)306 galKU42am galE trp $^{-}$am ara ${ }^{-}$am lac7 T6 ${ }^{\mathrm{R}}(\phi 80$ wt) (Kurnit, 1989). $\pi$ Flee and $\pi$ Flee-SOD were cloned in the $E$. coli K-12 strain MC1061: araD 139, $\Delta(a r a-l e u) 7697, \Delta a a X 74, g a l U^{-}$, galK ${ }^{-}, h s d R^{-}, s t r A, m c r A^{-}, m c r B^{-}$(Casadaban and Cohen, 1980; Raleigh et al., 1988).

b Recombination was performed in vivo in MC1061 [ $\pi$ Flee-SOD], and in MC1061 [ $\pi$ Flee] as a negative control (Table II; Seed, 1983).

c Following confluent lysis with Sumo15A and/or Sumo15A-SOD (Figs. 1 and 3), the resultant phage eluate was titered separately on the permissive Su host LE392 and on the selective Su' dnaB266am lacZ am host DK21 (Kurnit and Seed, 1990).

d The frequency of recombination was calculated as the ratio of pfu on DK21 to pfu on the permissive strain LE392 for a given aliquot of lysate.

- The dilution experiment was performed by increasing the ratio of Sumo15A phages (which did not recombine legitimately with $\pi$ Flee-SOD) to Sumo $15 A-S O D$ phages (which did recombine legitimately with $\pi$ Flee-SOD), resulting in progressively lower frequencies of recombination with $\pi$ Flee-SOD. At the greatest dilution of Sumo15A-SOD with Sumol5A, we retrieved two blue plaque phages carrying supF from ten 100 -mm DK21 screening-plate eluates of $100 \mu 1$, with a titer of $10^{10} \mathrm{pfu} / \mathrm{ml}$ on LE392. These blue plaque phage DNAs were analyzed on an agarose gel which showed the phages were indeed Sumo15A-SOD- $\pi$ Flee-SOD (Fig. 4).

derivatives and ColE1 supF plasmids. Phages isolated following recombination between Sumo15ASOD and $\pi$ Flee-SOD are denoted below as Sumo15A-SOD- $\pi$ Flee-SOD (Fig. 3).

(c) Reversal of the homologous recombination event: 'galactocide' selection against Sumo15A phasmids carrying supF

Although selection against expression of supF by lytically growing $\lambda$ phages has proven unfeasible to date (our unpublished data), selection against expression of supF has been realized in plasmids using appropriate auxotrophs of E. coli. Russell et al. (1970) demonstrated that exogenous galactose killed galK am $\mathrm{galE}^{-}$bacteria in the presence of a suppres- sor of the galKam gene: restoration of functional galactokinase activity by supF in the absence of the galactose epimerase resulted in toxic accumulation of UDP-galactose. We reasoned that this methodology could be used to select against expression of supF in Sumo15A phasmids that could propagate as plasmids in an appropriate galK am galE ${ }^{-}$host such as DK37. This galKam galE- trpam $\triangle$ recA ( $\phi 80 \mathrm{wt})$ host (Kurnit, 1989) propagates a Sumo15A phasmid as a plasmid driven by the $\mathrm{pGB} 2$ replicon, since the imm80 repressor prevents lytic growth of Sumo15A.

Our aim was to force deletion of the $\pi$ Flee plasmid and its insert by selection against supF. For example, in this manner, we could examine a cDNA sequence cloned in Sumo15A that was homologous to a genomic DNA sequence cloned in $\pi$ Flee without 


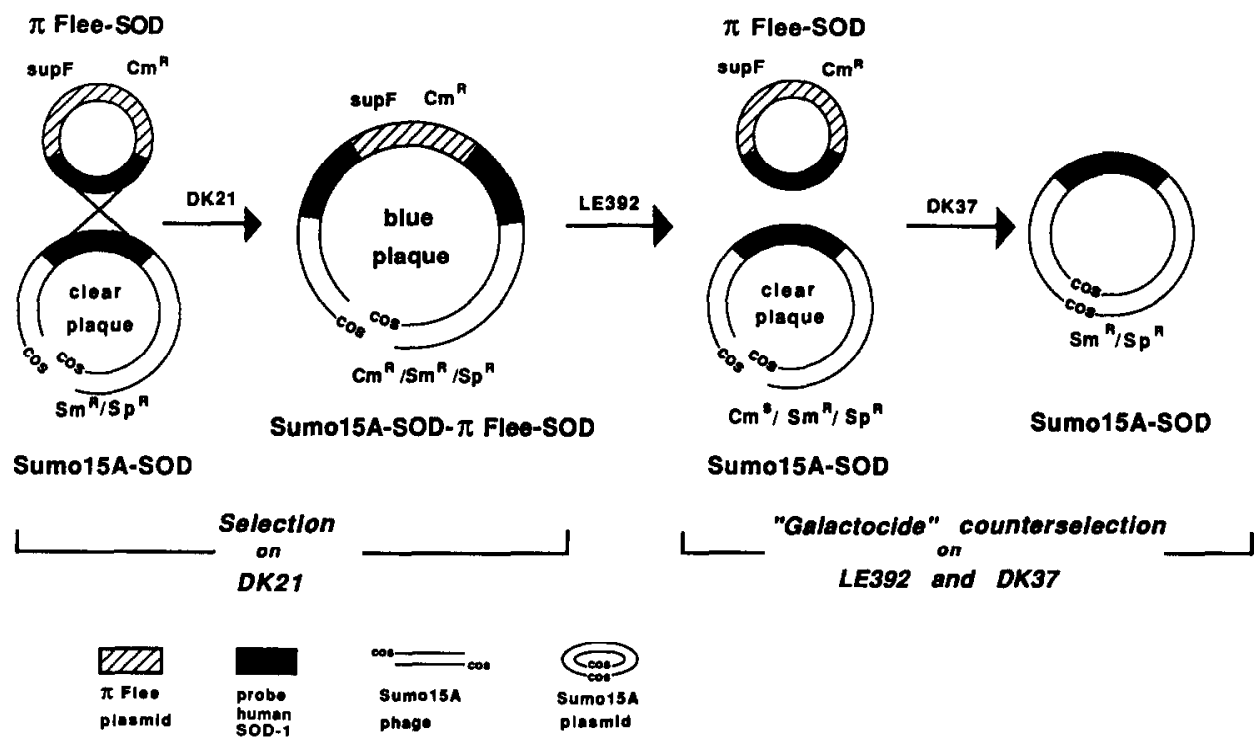

Fig. 3. Homologous recombination between $\pi$ Flee-SOD and Sumo15A-SOD, and regeneration of Sumo15A-SOD by counterselection. Ligation of the appropriate HindIII fragments was performed to construct the following:

(1) Sumol5A-SOD: a 1.3-kb HindIII human genomic DNA fragment from the human SOD-1 locus (Groner et al., 1985) inserted into the HindIII cloning site of SumolsA;

(2) $\pi$ Flee-SOD: the 1.3-kb HindIII human genomic SOD-1 fragment inserted into the HindIII cloning site of $\pi$ Flee (Fig. 2). For the recombination-based assay, $10^{7} \mathrm{pfu}$ of Sumo15A and/or Sumo15A-SOD were plated on $200 \mu \mathrm{l}$ of an overnight culture of MC1061 [ $\pi$ Flee-SOD]. Following confluent lysis, the resultant phage were eluted in $\phi 80$ diluent $(100 \mathrm{mM} \mathrm{NaCl} / 10 \mathrm{mM} \mathrm{MgCl} / 10 \mathrm{mM}$ Tris pH 7.4), and titered separately on the permissive Su host, LE392, and on the selective Sư dnaB 266am lacZ am host, DK21 (Kurnit and Seed, 1990). To plate on DK21 in this experiment, SumolSA-SOD must recombine with $\pi$ Flee-SOD to acquire sup $F$ and thus the ability to suppress amber mutations in the essential $\lambda$ phage $A$ and $B$ genes, and in the $d n a B$ gene of DK21. The integration of sup $F$ is established further using a colorimetric test to monitor suppression of the lac $Z$ am gene in DK21: phages harboring supF yield blue plaques on a white DK21 lawn in the presence of IPTG + Bluo-gal. The blue plaque phage so isolated is termed Sumo15A-SOD- $\pi$ Flee-SOD. To reverse the recombination event, the Sumo15A-SOD- $\pi$ Flee-SOD phage was eluted into $\phi 80$ diluent, and propagated on the Su recA ${ }^{+}$strain LE392, which permits recombination-based excision of $\pi$ Flee-SOD. Phasmids that have undergone such excision events can propagate as plasmids on DK37 on 'B' plates (which select against supF), but cannot propagate on 'A' plates (which select for sup $F$ ). This sequential process was performed by plating a Sumo15A-SOD- $\pi$ Flee-SOD phasmid onto a mixed lawn of LE392 and DK37, and streaking out the resulting turbid macroplaques onto 'B' plates. The resulting colonies were tested on ' $\mathrm{A}$ ' and ' $\mathrm{B}$ ' plates to ensure that they indeed grew on ' $\mathrm{B}$ ', but not on ' $\mathrm{A}$ ' plates. 'B' ${ }^{+},{ }^{\prime} \mathrm{A}$ ' - colonies carry the desired Sumo15A-SOD inserts.

interference from the genomic sequence (assuming that the genomic and genic sequences were essentially homologous). 'A' plates (that do not supply tryptophan; Table II) select for expression of supF by Sumo15A in the trpam host, DK37; 'B' plates (that contain galactose; Table II) select against expression of supF by Sumo15A in the galKam galE ${ }^{-}$host, DK37 (Russell et al., 1970; Kurnit, 1989). We demonstrated counterselection against supF in Sumo15A phasmids as follows. First, we showed that Sumo15A could propagate as a plasmid conferring $\mathrm{Sm}$ and $\mathrm{Sp}$ resistance. A mid-log culture of DK37 $\left(0.2 \mathrm{ml}\right.$ in LB with $\left.3 \mathrm{mM} \mathrm{Mg}^{2+}\right)$ was infected with $10^{6} \mathrm{pfu}$ of Sumo15A, allowed to grow for $1 \mathrm{~h}$ in the absence of selection, and then plated on $\mathrm{Sm}+\mathrm{Sp}$ plates yielding $1 \times 10^{3}$ colonies, an efficiency of $1 \times 10^{-3} \mathrm{cfu} / \mathrm{pfu}$. This efficiency was constant, regardless of whether the plates contained galactose. We then determined the efficiency of establishment of Sumo15A phages carrying $\pi$ Flee (supF $\mathrm{Cm}^{\mathrm{R}}$ ) derivatives as plasmids in DK37 in the presence or absence of galactose. ' $A$ ' plates, that do not supply tryptophan, were used to select for propagation of $\pi$ Flee in Sumo15A; 'B' plates, that contain galactose, were used to select against propagation of $\pi$ Flee in Sumo15A. As shown in Table II, the efficiency of establishment of Sumo15A as a plasmid in DK37 on LB Sm + Sp ('C') plates was 
TABLE II

Infection of DK37 by Sumo15A and its derivatives ${ }^{\text {a }}$

Phasmid ${ }^{b}$

Efficiency of establishment as a plasmid (cfu/pfu)

after infection of $\mathrm{DK} 37^{\mathrm{C}}$

\begin{tabular}{llll} 
& Plate 'A' & Plate 'B' & Plate 'C' \\
\hline Sumol5A & 0 & $1 \times 10^{-3}$ & $1 \times 10^{-3}$ \\
Sumo15A-SOD & 0 & $1 \times 10^{-3}$ & $1 \times 10^{-3}$ \\
Sumo15A- $\pi$ Flee & $1 \times 10^{-3}$ & $1 \times 10^{-7 d}$ & $1 \times 10^{-3}$ \\
Sumo15A-SOD- $\pi$ Flee-SOD & $1 \times 10^{-4}$ & $1 \times 10^{-3 e}$ & $1 \times 10^{-4}$ \\
\hline
\end{tabular}

a 'A' plates, used to select for joint propagation of both Sumo15A and $\pi$ Flee in DK37 (conferring a $\mathrm{Su} \mathrm{Cm}^{\mathrm{R}} \mathrm{Sm}^{\mathrm{R}} \mathrm{Sp}^{\mathrm{R}} \mathrm{genotype}$ ), contained M9 salts + Casamino acids (Difco; $10 \mathrm{mg} / \mathrm{ml})+$ glycerol $(2 \mathrm{mg} / \mathrm{ml})+25 \mu \mathrm{g} \mathrm{Cm} / \mathrm{ml}+100 \mu \mathrm{g} \mathrm{Sm} / \mathrm{ml}+50 \mu \mathrm{g} \mathrm{Sp} / \mathrm{ml}$. 'B' plates, used to select for propagation of Sumol5A and against propagation of $\pi$ Flee in DK37, contained M9 salts + Casamino acids (Difco; $10 \mathrm{mg} / \mathrm{ml})+$ glycerol $(2 \mathrm{mg} / \mathrm{ml})+$ galactose $(2 \mathrm{mg} / \mathrm{ml})+$ tryptophan $(20 \mu \mathrm{g} / \mathrm{ml})+100 \mu \mathrm{g} \mathrm{Sm} / \mathrm{ml}+50 \mu \mathrm{g} \mathrm{Sp} / \mathrm{ml}$. 'C plates, used to select for propagation of Sumo15A without regard to propagation of $\pi$ Flee in DK37, were LB plates $+100 \mu \mathrm{g} \mathrm{Sm} / \mathrm{ml}+50 \mu \mathrm{g} \mathrm{Sp} / \mathrm{ml}$.

b The construction of phasmid Sumo15A is outlined in Fig. 1. Sumol5A-SOD and Sumo15A- $\pi$ Flee were constructed by inserting the HindIII fragments corresponding to $S O D-1$ and $\pi$ Flee, respectively, into the unique HindIII cloning site of Sumol5A. Sumo15A-SOD- $\pi$ Flee-SOD was created by recombining Sumo15A-SOD with $\pi$ Flee-SOD (Fig. 3).

- The number of cfu was determined after infection of a mid-log culture of DK37. The number of pfu was determined following infection of the permissive host, LE392. The genotypes of DK37 and LE392 are given in Table I.

d As discussed in section c, these bacteria were uniformly galE ${ }^{+}$revertants that had not deleted supF.

- As discussed in section c, this number was $10^{-5}$ if the phage were passaged through a recA ${ }^{+}$host first, and consisted in the main of phasmids that had deleted supF.

independent of the presence of supF in Sumo15A (compare Sumol5A and Sumo15A- $\pi$ Flee). In contrast, the efficiency of establishment of SumolsASOD- $\pi$ Flee-SOD as a plasmid in DK37 on 'A' or 'C' plates was ten-fold lower (Table II), presumably due to difficulties inherent in establishing a plasmid that contains direct repeats of the $S O D-1$ sequence (Seed, 1983).

We detected infection with $\pi$ Flee, that conferred a $\mathrm{Su} \mathrm{Cm}^{\mathrm{R}}$ genotype, as follows. Infection with Sumo15A or Sumo15A-SOD (both $\mathrm{Su}^{\circ} \mathrm{Cm}^{\mathrm{S}} \mathrm{Sm}^{\mathrm{R}}$ $\mathrm{Sp}^{\mathrm{R}}$ ) did not change the $\mathrm{Su}^{\circ} \mathrm{Cm}^{\mathrm{S}}$ genotype of DK37, although resistance to $\mathrm{Sm}$ and $\mathrm{Sp}$ was conferred. The resulting $\mathrm{Su}^{\circ} \mathrm{Cm}^{\mathrm{S}} \mathrm{Sm}^{\mathrm{R}} \mathrm{Sp}^{\mathrm{R}}$ colonies propagated on ' $\mathrm{B}$ ' and ' $\mathrm{C}$ ' plates, but did not propagate on ' $A$ ' plates. Infection of DK37 with Sumo15A- $\pi$ Flee yielded a cell that carried both the supF gene and the $\mathrm{Cm}^{\mathrm{R}}$ gene on $\pi$ Flee, as well as the $\mathrm{Sm}^{\mathrm{R}}$ and $\mathrm{Sp}^{\mathrm{R}}$ genes on Sumo15A. The resultant $\mathrm{Su}$ $\mathrm{Cm}^{\mathrm{R}} \mathrm{Sm}^{\mathrm{R}} \mathrm{Sp}^{\mathrm{R}}$ genotype of DK37 yielded colonies on both ' $A$ ' and ' $C$ ' plates ( $\mathrm{cfu} / \mathrm{pfu}=1 \times 10^{-3}$ ); the rare colonies obtained on ' $B$ ' plates were uniformly Su $\mathrm{Cm}^{\mathbf{R}}$, indicating that $\pi$ Flee was still present (cfu/pfu $=10^{-7}$ ). These infrequent $\mathrm{Su} \mathrm{Cm}^{\mathrm{R}}$ colonies manifested a galE ${ }^{+}$genotype, as they grew on plates with galactose as the sole carbon source. Infection by Sumo15A-SOD- $\pi$ Flee-SOD gave approximately the same frequency of colonies on ' $A$ ' and ' $C$ ' plates $\left(10^{-4}\right)$ and rare $\left(10^{-7}\right) \mathrm{Su} \mathrm{Cm}^{\mathrm{R}}$ colonies on ' $B$ ' plates (indicating the continued presence of $\pi$ Flee), if the phage was taken directly from a stock propagated on DK21. However, if the stock was passaged on the permissive Su recA ${ }^{+}$strain, LE392, before infection of DK37, the efficiency of establishment in DK37 on 'B' plates increased to $10^{-5}$, and the resultant colonies were usually $\mathrm{Su}^{\circ} \mathrm{Cm}^{\mathrm{S}}$ (no growth on 'A' plates) reflecting excision of $\pi$ Flee via recombination between the $S O D$ direct repeats (Fig. 3). Perry and Moran (1987) previously reported that excision of sup $F$ plasmids from amber phage via homologous recombination depended upon prior passage through a permissive $\mathrm{Su} r e c A^{+}$host, such as LE392. In this host, recombination can occur because of the $r e c A^{+}$genotype, and recombinants that have eliminated $\pi$ Flee (and $s u p F$ ) can propagate as phages because of the Su genotype. 


\section{(d) Streamlining the counterselection procedure}

To minimize expenditures of material and personnel time, the following procedure is used to select against Sumo15A carrying supF. Selection of a blue plaque on DK21 in the presence of IPTG and Bluogal (demonstrating suppression of the lacZam allele of DK21) indicates a $\lambda$ phage that has acquired the sup $F$-containing plasmid $\pi$ Flee via homologous recombination between an insert carried by both the Sumo15A phage and the $s u p F$ plasmid, $\pi$ Flee $(\sup F$ suppresses the dnaBam and lacZam alleles in DK21; Kurnit and Seed, 1990; Fig. 3). The phage plaque is eluted into $50 \mu \mathrm{l}$ of $\phi 80$ diluent $(100 \mathrm{mM}$ $\mathrm{NaCl} / 10 \mathrm{mM} \mathrm{MgCl}_{2} / 10 \mathrm{mM}$ Tris $\left.\mathrm{pH} 7.4\right)+5 \mu \mathrm{l}$ chloroform and vortexed for $30 \mathrm{~s}$ at top speed. A plate is prepared by adding $100 \mu \mathrm{l}$ of overnight culture each of DK37 and LE392 to $3 \mathrm{ml}$ of top agar, which is then poured, allowed to harden, and incubated at $37^{\circ} \mathrm{C}$. Three successive $1 / 100$ dilutions are made of the phage eluate, and $10 \mu \mathrm{l}$ of the original eluate and each dilution are spotted individually onto the mixed LE392-DK37 lawn. The result is a series of turbid plaques, resulting from lytic propagation on the permissive strain (LE392) of Sumo15A phasmids that then infect and establish as plasmids in the restrictive host (DK37). Working from the turbid spot derived from the lowest titer phage dilution that yields confluent lysis on the mixed LE392-DK37 lawn, bacteria are streaked with a sterile loop onto 'B' plates to select for DK37 colonies harboring phasmids that excised $\pi$ Flee during propagation through LE392 before infecting DK37. The resultant colonies are gridded on 'A' and 'B' plates; $\mathrm{Su}^{\circ} \mathrm{Cm}^{\mathrm{S}}$ colonies that propagate on ' $B$ ' plates, but not on ' $A$ ' plates (which support $\mathrm{Su} \mathrm{Cm}^{\mathrm{R}}$ colonies), are the desired colonies that contain Sumol5A phasmids that have excised $\pi$ Flee.

\section{(e) Analysis of phasmid DNA confirms the genetic evidence for counterselection}

We documented that the genetic selection against supF indeed selected phasmids that had excised the supF-containing $\pi$ Flee-SOD plasmid from the original Sumo15A-SOD- $\pi$ Flee-SOD phasmid. Fig. 4a shows restriction digests of plasmid DNA preparations derived after infection of DK37 with different Sumo15A-derived phasmids. Lane 1 is a control of

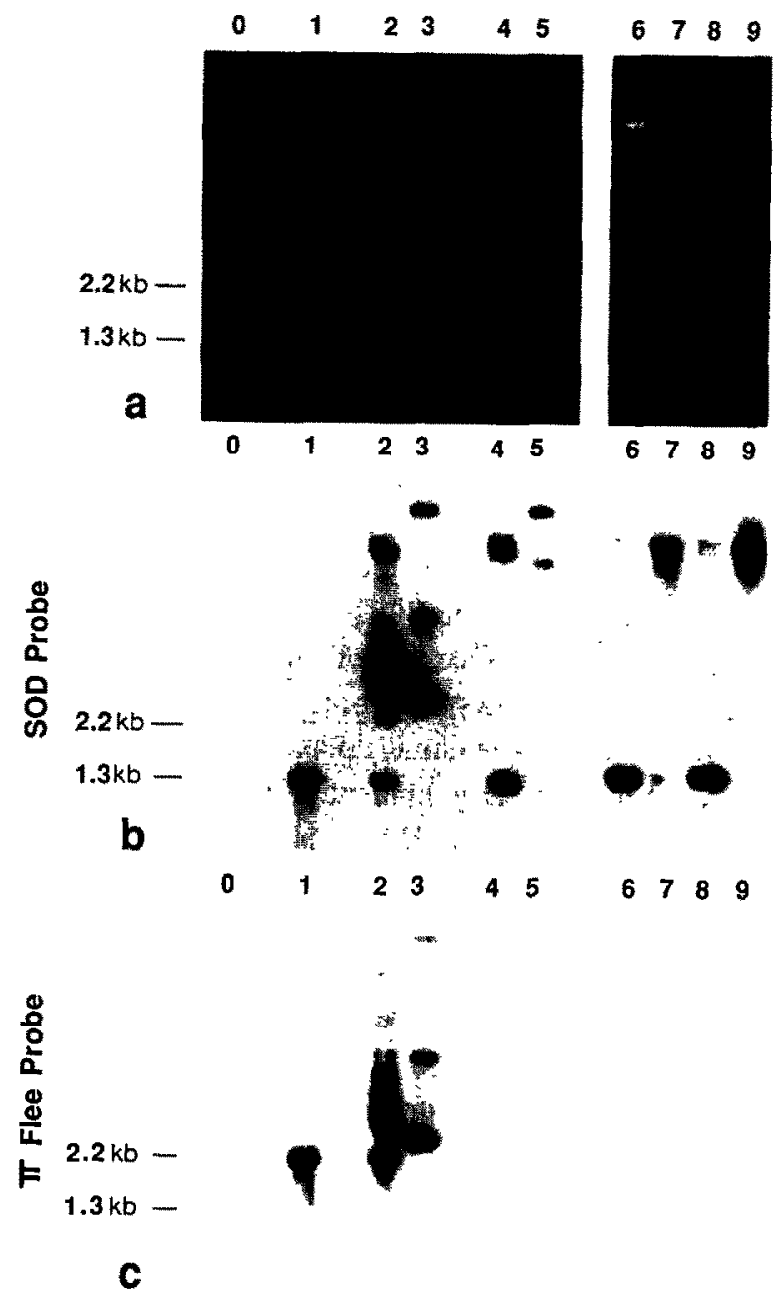

Fig. 4. Physical evidence for recombination-based assay and counterselection. Plasmid DNA preparations were derived from colonies on ' $A$ ' plates (selected for supF) and colonies on ' $B$ ' plates (selected against supF) as described in Table II and sections $\mathrm{c}$ and $\mathrm{e}$. Where indicated below, each DNA preparation was digested by $H$ indIII for $4 \mathrm{~h}$ at $37^{\circ} \mathrm{C}$. The DNA samples were loaded on an $0.8 \%$ agarose gel (pH 8.6) for electrophoresis. (Panel a) EtdBr-stained gel. The gel was denatured, transferred to a Genatran (Plasco) filter, and hybridized to $S O D-1$ probe (panel b) and to $\pi$ Flee-probe (panel c). Lanes: 1 (control), HindIII-digested $\pi$ Flee-SOD; 2, HindIII-digested plasmid DNA derived from 'A' plates; 3 , undigested plasmid DNA of lane 2; 4, HindIII-digested plasmid DNA derived from ' $B$ ' plates; 5, undigested plasmid DNA of lane 4; lanes 6-9 depict the plasmid DNA derived from two phasmids isolated at the greatest $\left(10^{7}: 1\right)$ dilution of Sumo15A-SOD by Sumo15A as described in section $b$ and Table $I$. Lanes 6 and 8 contain HindIII-digested DNAs, lanes 7 and 9 contain undigested DNAs. 
HindIII-digested $\pi$ Flee-SOD, yielding the expected $2.2-\mathrm{kb} \pi$ Flee vector and $1.3-\mathrm{kb} S O D$ insert fragments. Lane 2 represents HindIII-digested plasmid DNA obtained following infection of DK37 with Sumo15A-SOD- $\pi$ Flee-SOD (selected initially as a blue plaque on DK21, followed by infection into DK37, yielding $\mathrm{Su} \mathrm{Cm}^{\mathrm{R}}$ colonies on 'A' plates). We indeed obtained Sumo15A-SOD phasmids that integrated $\pi$ Flee-SOD, as the expected HindIII fragments corresponding to both $\pi$ Flee and SOD are present. Lane 3 represents undigested phasmid DNA. We note that the undigested DNA preparation (lane 3) shows two distinct plasmids, Sumo15A-SOD- $\pi$ Flee-SOD and $\pi$ Flee-SOD: hybridization of $\pi$ Flee to both the small and large plasmid bands shows that copies of $\pi$ Flee-SOD are present both as free (small) plasmid and integrated in the Sumo15A (large) plasmid. This was noted in multiple independent DNA preparations. Thus, although DK 37 is a $\triangle r e c A$ host (Kurnit, 1989), free copies of $\pi$ Flee-SOD are derived (presumably) from Sumo15A-SOD- $\pi$ Flee-SOD via recombination between the SOD direct repeats. We speculate that this recombination event could be promoted by residual phage $\lambda$ red expressed by Sumo15A shortly after infection before the plasmid state (and repression) is fully realized. Lanes 4-9 depict plasmid DNA derived from counterselection against supF of the Sumo15A-SOD- $\pi$ Flee-SOD phage shown in lanes 2 and 3. Following selection for supF on DK21, the phasmid was propagated as a lytic phage on the Su recA ${ }^{+}$strain LE392, and then infected into DK37 and selected as a plasmid on 'B' (glycerolgalactose) plates to counterselect against supF. In lane 5, undigested plasmid DNA reveals a single large plasmid. In lane 4, HindIII digestion yields a linearized Sumo15A DNA fragment (about $40 \mathrm{~kb}$ ) and the $1.3-\mathrm{kb} S O D-1$ insert carried by the initial Sumo15A-SOD phage before the recombination event. Confirming the expectation based on the $\mathrm{Su}^{\circ}$ $\mathrm{Cm}^{\mathrm{S}}$ genotype that $\pi$ Flee was excised prior to infection of DK37, no 2.2-kb fragment corresponding to $\pi$ Flee is visible in lane 4 . Lanes $6-9$ depict phasmid DNAs obtained by the streamlined counterselection protocol. In lanes $6-9$, the Sumo15A-SOD- $\pi$ FleeSOD phages chosen for counterselection were obtained from the reconstruction experiment $\left(10^{-7}\right.$ dilution) in Table I. The results are indistinguishable from lanes 4 and 5. Hybridization with radiolabeled $\pi$ Flee and $S O D-1$ probes, respectively, corroborated these interpretations (Fig. 4,b and c).

\section{(f) Conclusions}

Taken together, these results illustrate the power of the selection: we achieved $10^{7}$-fold purification of Sumo15A-SOD from Sumo15A by a two-step protocol. First, we selected for a Sumo15A-SOD- $\pi$ FleeSOD chimera generated via homologous recombination between the $S O D-1$ inserts in Sumo15A-SOD and $\pi$ Flee-SOD; second, we selected for excision of $\pi$ Flee-SOD from Sumo15A-SOD- $\pi$ Flee-SOD to regenerate the original Sumo15A-SOD phasmid (Table I and Fig. 4).

This protocol will permit rapid determination of whether a genomic sequence is transcribed (or represents a closely related pseudogene) as evidenced by the existence of homology between a genomic sequence cloned in $\pi$ Flee and a gene sequence (cDNA) cloned in Sumo15A. Specifically, we will use this assay to isolate genes encoded by human chromosome 21, which yields Down's syndrome when present in three copies. The method described here may also allow one to find the polymorphic sequences of some organisms and/or related sequences of different organisms (Seed, 1983).

As discussed by Lutz et al. (1987) and Huang et al. (1987), the recombination-based method is best suited to the case of complete or nearly complete homology between probe and target sequences. Our method increases such specificity by enabling us to examine both the forward and reverse rates of recombination. In this respect, we have extended the specificity of the recombination-based assay.

To datc, two problems have confounded widespread use of the recombination-based assay for the molecular dissection of complex genomes: (1) background in the assay, and (2) integration of the sup $F$ plasmid and probe nt sequence into the phage retrieved via recombination prevents mapping solely the phage insert. Recently, we described the specialized dnaB266am host, DK21, that eliminated the background problem (Kurnit and Seed, 1990). Here, we describe the construction of a phasmid vector, Sumo15A, and a host, DK37, that together circumvent the second problem for homologous (or nearly homologous) recombination events: this vector-host system yields a facile selection for phasmids 
that have deleted the supF plasmid and probe nt sequence. For the particular case where perfect (or near perfect) homology is expected, such as between the genomic and genic (cDNA) correlates of a sequence, the counterselection frequency will be high. In this case, counterselection will regenerate the genic phasmid much as it existed before the recombination event.

\section{ACKNOWLEDGEMENTS}

We thank Dr. Y. Groner for providing SOD-1 probe and $F$. Lee for providing $\pi$ Flee plasmid. We thank Drs. M. Levine, F. Collins, B. Seed, M. Van Keuren, G. Stewart, K. Kurachi, D. Friedman and F. Neidhardt for their comments. Supported by NIH HD20118 and March of Dimes 6-501. D.M.K. is an Investigator, Howard Hughes Medical Institute.

\section{REFERENCES}

Blattner, F.R., Williams, B.G., Blechl, A.E., DennistonThompson, K., Faber, H.E., Furlong, L.-A., Grunwald, D.J., Kiefer, D.O., Moore, D.D., Schumm, J.W., Sheldon, E.L. and Smithies, O.: Charon phages: safer derivatives of bacteriophage lambda for DNA cloning. Science 196 (1977) 161-169.

Casadaban, M.J. and Cohen, S.N.: Analysis of gene control signals by DNA fusion and cloning in Escherichia coli. J. Mol. Biol. 138 (1980) 179-207.

Churchward, G., Belin, D. and Nagamine, Y.: A pSC101-derived plasmid which shows no sequence homology to other commonly used cloning vectors. Gene 31 (1984) 165-171.

Groner, Y., Lieman-Hurwitz, J., Dafni, N., Sherman, L., Levanon, D., Bernstein, Y., Danciger, E. and Elroy-Stein, O.: Molecular structure and expression of the gene locus on chromosome 21 encoding the $\mathrm{Cu} / \mathrm{Zn}$ superoxide dismutase and its relevance to Down syndrome. Ann. N.Y. Acad. Sci. 450 (1985) 133-156.

Huang, H.V., Little, P.F.R. and Seed, B.: Improved suppressor tRNA cloning vehicles and plasmid-phage recombination. In
Rodriguez, R.L. and Denhardt, D.T. (Eds.), Vectors: A Survey of Molecular Cloning Vectors and Their Uses. Butterworths, Stoneham, MA, 1987, pp. 269-283.

Ikeda, H., Aoki, K. and Naito, A.: Illegitimate recombination mediated in vitro by DNA gyrase of Escherichia coli: Structure of recombinant DNA molecules. Proc. Natl. Acad. Sci. USA 79 (1982) 3724-3728.

Kurnit, D.M.: Escherichia coli recA deletion strains that are highly competent for transformation and for in vivo packaging. Gene 82 (1989) 313-315.

Kurnit, D.M. and Seed, B.: Bacterial strains for screening bactcriophage librarics by homologous recombination in vivo. Proc. Natl. Acad. Sci. USA (1990) in press.

Lindahl, G., Sironi, G., Bialy, H. and Calendar, R.: Bacteriophage lambda: abortive infection of bacteria lysogenic for phage P2. Proc. Natl. Acad. Sci. USA 66 (1970) 587-594.

Linder, P., Churchward, G. and Caro, L.: Plasmid pSC101 replication mutants generated by insertion of transposon $\mathrm{Tn} 1000$. J. Mol. Biol. 170 (1983) 287-303.

Lutz, C.T., Hollifield, W.C., Seed, B., Davie, J.M. and Huang, H.V.: Syrinx 2A: an improved $\lambda$ phage vector designed for screening DNA libraries by recombination in vivo. Proc. Natl. Acad. Sci. USA 84 (1987) 4379-4383.

Marvo, S.L., King, S.R. and Jaskunas, S.R.: Role of short regions of homology in intermolecular illegitimate recombination events. Proc. Natl. Acad. Sci. USA 80 (1983) 2452-2456.

Neve, R.L. and Kurnit, D.M.: Comparison of sequence repetitiveness of human CDNA and genomic DNA using the miniplasmid vector, piVX. Gene 23 (1983) 355-367.

Perry, M.D. and Moran, L.A.: Isolation of a mouse heat-shock gene ( $h s p 68$ ) by recombinational screening. Gene 51 (1987) 227-236.

Raleigh, E.A., Murray, N.E., Revel, H., Blumenthal, R.M., Westaway, D., Reith, A.D., Rigby, P.W.J., Elhai, J. and Hanahan, D.: McrA and McrB restriction phenotypes of some $E$. coli strains and implications for gene cloning. Nucleic Acids Res. 16 (1988) 1563-1575.

Russell, R.L., Abelson, J.N., Landy, A., Gefter, M.L., Brenner, S. and Smith, J.D.: Duplicate genes for tyrosine transfer RNA in Escherichia coli. J. Mol. Biol. 47 (1970) 1-13.

Seed, B.: Purification of genomic sequence from bacteriophage libraries by recombination and selection in vivo. Nucleic Acids Res. 11 (1983) 2427-2445.

Vieira, J. and Messing, J.: The pUC plasmids, an M13mp7derived system for insertion mutagenesis and sequencing with synthetic universal primers. Gene 19 (1982) 259-268. 